\title{
Application of differential scanning calorimetry to study porous structure of hydrothermally modified silicas
}

\author{
B. Charmas ${ }^{1} \cdot$ J. Skubiszewska-Zięba ${ }^{1}$
}

Received: 12 November 2016/Accepted: 24 January 2017/Published online: 8 February 2017

(C) The Author(s) 2017. This article is published with open access at Springerlink.com

\begin{abstract}
The paper presents the studies on determination of physicochemical and structural properties of hydrothermally treated (HTT) silica gel Si-60, using the differential scanning calorimetry (DSC) and $\mathrm{N}_{2}$ adsorption methods. Modification was performed in overheated water vapours or under the liquid water layer using various sources of thermal energy (in the classical autoclave or in the high-pressure microwave reactor). The characteristics of porous structure were determined on the basis of low-temperature nitrogen adsorption/desorption isotherms and using the calorimetric data (DSC) of thermal effects of phase transition of water introduced inside pores of the studied materials. Great compatibility of the characteristics obtained by means of the above-mentioned methods was proved. As follows from the SEM analysis, during HTT silica is rebuilt resulting in great changes of surface morphology and porous structure of the materials. The range of these changes depends on both the applied system (water vapour/liquid water) and the kind of used energy (classical/microwave).
\end{abstract}

Keywords Silica gel · Hydrothermal modification - DSC · Porous structure

\section{Introduction}

Porous silica gels are widely applied in numerous fields of modern science and technology as adsorbents, catalyst carriers, polymer fillers and chromatographic column

B. Charmas

barbara.charmas@poczta.umcs.lublin.pl

1 Faculty of Chemistry, Maria Curie-Sklodowska University, Maria Curie-Sklodowska Sq. 3, 20-031 Lublin, Poland packings. Such extended applications result from mechanical and thermal resistance, developed specific surface area as well as defined structure of pores [1, 2]. A wide range of possible silica gel applications requires preparation of new materials of different surface characteristics. Hydrothermal modification (HTT) is one of the most frequently used and most effective methods for adjusting textural and structural parameters of the surface of adsorbents and catalysts [3-8]. The hydrothermal modification consists in subjecting the material to the action of water (in the liquid or gaseous state) at a temperature over $100{ }^{\circ} \mathrm{C}$ under pressure higher than the atmospheric one. Silica gels are practically susceptible to the action of water vapour in such a system [9]. Under these conditions, its tetrahedral structure changes, hydrogen bonds disrupt, and as a result, the physicochemical parameters of water also change. Consequently, its capacity of dissolution of solid increases. Hydrothermal treatment of silica consists in depolymerization of small particles to the orthosilicic acid form followed by its condensation on larger particles. Thorough analysis of hydrothermal modification results is essential as it facilitates prediction of changes of adsorbent and catalyst properties which take place during numerous technological processes run at high temperatures, often in the presence of water. The results of HTT depend on the structure of initial adsorbent, temperature, time and process conditions (gaseous or liquid phases) as well as $\mathrm{pH}$ of the used medium [3-9]. Due to such modification, there are changes, among others, of specific surface area, size and structure of pores as well as chemical character of the surface.

Changes of the porous structure and surface properties of silica gel due to HTT (dissolving properties of $\mathrm{H}_{2} \mathrm{O}$ ) result in the changes of accessibility of water molecules (or other media) and interactions with the surface of studied 
materials. This type of interactions is studied, among others, by differential scanning calorimetry (DSC) providing essential information about porous structure of the studied materials [10-21]. The method consists in studying phase solid/liquid transitions of the media contained in pores [15]. This method was described for the first time by Brun et al. [16] establishing a thermodynamic background of calorimetric determination of porous structure of solid materials on the basis of thermal effects connected with liquid freezing in pores. It was proved that these changes are closely connected with pore sizes in the studied materials $[11,22,23]$. The studies make use of the fact that inside the porous structure of mesoporous materials, there is freezing water (forming ice crystals, no bound or weakly bound with the pore surface) and water not freezing in pores (which does not undergo phase transition during freezing or melting, strongly bound with the pore walls). This differentiates thermal effects $(\Delta H)$ observed during freezing of water and melting of ice crystals inside the pores.

The aim of the paper was to study the application of adsorption $\left(\mathrm{N}_{2}\right)$ and calorimetric (DSC) methods to determine the porous structure and surface morphology (SEM) of hydrothermally treated (HTT) silica gel Si-60. Modification was performed in overheated water vapours or under the liquid water layer, using various sources of thermal energy (in the classical autoclave or in the high-pressure microwave reactor).

\section{Materials and methods}

\section{Materials}

As the initial material there was used a mesoporous silica gel Si-60 (Merck, Germany) of the grain size $d=$ $0.3-0.5 \mathrm{~mm}$, the specific surface area $S_{\mathrm{BET}}=464.5 \mathrm{~m}^{2} \mathrm{~g}^{-1}$ and the pore volume $V_{\mathrm{p}}=0.85 \mathrm{~cm}^{3} \mathrm{~g}^{-1}$. Before modification, the gel was dried at $200{ }^{\circ} \mathrm{C}$ in order to remove physically adsorbed water. Hydrothermal modification was conducted under a layer of liquid water and in the atmosphere of overheated water vapour. The modifications were performed in the microwave reactor (NANO-2000, Plazmatronika, Poland) and in the classical steel autoclave $\left(0.3 \mathrm{dm}^{3}\right)$. Modifications in the microwave reactor were carried out under different conditions of time (5-100 min), pressure (20-70 atm) and temperature $\left(220-290{ }^{\circ} \mathrm{C}\right)$. In both procedures, the values of temperature and time were the same, but the values of pressure were some different. It is because the fact that during microwave heating is possible to set the maximum pressure, which determines the maximum of temperature, while in the case of modification in the autoclave the saturated water pressure is related to temperature of the system [24]. The detailed information about the preparation and modification of the materials under discussion is presented in paper [9]. According to the applied procedure, the obtained samples were denoted as $\mathrm{Si}-60_{\text {ini }}$ (initial silica gel), $\mathrm{Si}-x_{\mathrm{m}-\mathrm{vap}}, \mathrm{Si}-x_{\mathrm{m}-\mathrm{liq}}, \mathrm{Si}-x_{\mathrm{a}-\mathrm{vap}}$ and $\mathrm{Si}-x_{\mathrm{a}-\mathrm{liq}}$ ( $m$ means modification in the microwave reactor, $a-\mathrm{HTT}$ in the steel reactor, vap-modification in the atmosphere of overheated water vapour, liq - under the layer of liquid water but $x$ means a successive number of the sample. The preparation conditions of silica adsorbents modified in the microwave reactor or in the autoclave are presented in Table 1.

\section{$\mathbf{N}_{2}$ adsorption}

In order to calculate the structural parameters of the studied samples, there were used the data of low-temperature $\left(-196^{\circ} \mathrm{C}\right)$ nitrogen adsorption/desorption isotherms (Micromeritics, ASAP 2405N, V1.01, Norcross, USA). Before the $\mathrm{N}_{2}$ adsorption analysis, the silica gels were degassed at $150{ }^{\circ} \mathrm{C}$ until equilibrium was reached in the burette at a pressure of $5 \times 10^{-3}$ Torr. The specific surface area $\left(S_{\mathrm{BET}}\right)$ was determined using the standard BET equation [25]. The total pore volume $V_{\mathrm{p}}$ was determined at $p / p_{\mathrm{o}} \approx 0.98$ ( $p$ and $p_{\mathrm{o}}$ denote the equilibrium pressure and the saturation pressure of nitrogen at $-196{ }^{\circ} \mathrm{C}$, respectively). The accuracy of measurements was $2.69 \%$. The nitrogen desorption data were used to compute the pore size distribution $\left(\mathrm{PSD}_{\mathrm{v}}\right.$, $\mathrm{d} V / \mathrm{d} R=\mathrm{f}(R))$. Calculations were based on the self-consistent regularization procedure (SCR) under the non-negativity condition $\left(\mathrm{f}\left(R_{\mathrm{p}}\right)>0\right.$ at any pore radius $\left.\mathrm{R}\right)$ at the fixed value of the regularization parameter $\alpha=0.01$ with the complex pore model with cylindrical pores and voids between the spherical nanoparticles packed in random aggregates (SCV model) [11, 26, 27]. The differential PSDs with respect to pore volume were re-calculated as incremental PSD ( $\left.\operatorname{IPSD}_{\mathrm{v}}\right)$. In the calculations, there was estimated contribution of individual kinds of pores: nanopores ( $V_{\text {nano }}, S_{\text {nano }}$ for $\left.R_{\mathrm{p}}<1 \mathrm{~nm}\right)$, mesopores $\left(V_{\text {meso }}, S_{\text {meso }}\right.$ for $\left.1 \mathrm{~nm}<R_{\mathrm{p}}<25 \mathrm{~nm}\right)$ and macropores $\left(V_{\text {macro }}, S_{\text {macro }}\right.$ for $R_{\mathrm{p}}>25 \mathrm{~nm}$ ) [11, 26-31]. The pores of nanosize radii $(R<1 \mathrm{~nm})$ were designated as the "nanopores" $[11,27]$.

\section{TG analysis}

Derivatographic measurements were taken on the apparatus Derivatograph-C (Paulik, Paulik \& Erdey, MOM, Hungary). The water vapour was adsorbed on the silica gels surface at $20^{\circ} \mathrm{C}$. A portion (ca. $1 \mathrm{~g}$ ) of adsorbent was placed in a desiccator containing bidistilled liquid water for $72 \mathrm{~h}$. Then, the weighed portions (ca. $50 \mathrm{mg}$ ) of the adsorbents were placed in a corundum crucible of the 
Table 1 The preparation conditions of silica adsorbents modified in the microwave reactor or in the autoclave [9]

\begin{tabular}{|c|c|c|c|c|c|}
\hline Sample (microwave) & $t / \min$ & $p_{\mathrm{m}} / \mathrm{atm}$ & $T /{ }^{\circ} \mathrm{C}$ & Sample (autoclave) & $p_{\mathrm{m}} / \mathrm{atm}$ \\
\hline Si-1 ${ }_{\text {m-liq }}$ & 7 & 60 & 290 & - & - \\
\hline Si- $2_{\mathrm{m}-\mathrm{liq}}$ & 40 & 60 & 270 & Si-2 2 -liq & 54 \\
\hline Si-3 ${ }_{\mathrm{m}-\mathrm{liq}}$ & 60 & 70 & 280 & $\mathrm{Si}-3_{\mathrm{a}-\mathrm{liq}}$ & 63 \\
\hline Si-4m-liq & 70 & 40 & 230 & $\mathrm{Si}-4_{\mathrm{a}-\mathrm{liq}}$ & 28 \\
\hline Si-5m-liq & 100 & 20 & 230 & $\mathrm{Si}-5_{\mathrm{a}-\mathrm{liq}}$ & 28 \\
\hline Si- $6_{m-l i q}$ & 100 & 60 & 270 & Si-6 $6_{\mathrm{a}-\mathrm{liq}}$ & 54 \\
\hline Si-1 $1_{\text {m-vap }}$ & 5 & 60 & 275 & - & - \\
\hline $\mathrm{Si}-2_{\mathrm{m}-\mathrm{vap}}$ & 40 & 60 & 270 & Si-2 $\mathrm{a-vap}$ & 54 \\
\hline $\mathrm{Si}-3_{\mathrm{m}-\mathrm{vap}}$ & 60 & 70 & 280 & Si-3 $\mathrm{a-vap}$ & 63 \\
\hline $\mathrm{Si}-4_{\text {m-vap }}$ & 70 & 40 & 220 & $\mathrm{Si}-4_{\mathrm{a}-\mathrm{vap}}$ & 23 \\
\hline $\mathrm{Si}-5_{\mathrm{m}-\mathrm{vap}}$ & 100 & 20 & 230 & Si-5 a-vap & 28 \\
\hline Si- $6_{m-v a p}$ & 100 & 60 & 270 & Si-6 $6_{\text {a-vap }}$ & 54 \\
\hline
\end{tabular}

derivatograph. The investigations were carried out with the linear temperature increase $\left(10{ }^{\circ} \mathrm{C} \mathrm{min}^{-1}\right)$ in air atmosphere in the temperature range $20-200{ }^{\circ} \mathrm{C}$. From the obtained results, the degree of saturation of the studied materials with water was determined. These data were necessary to evaluate of changes of the phase transition enthalpy $(\Delta H)$ from the DSC data.

\section{Differential scanning calorimetry}

Calorimetric studies were carried out using a differential scanning calorimeter (DSC PYRIS Diamond, PerkinElmer, USA). The weighed samples (saturated with water vapour, see in $T G$ analysis, samples mass about $15 \mathrm{mg}$ ) were closed in aluminium pans. Studies of water freezing and melting for all samples were carried out in the temperature range (from +20 to $-170{ }^{\circ} \mathrm{C}$ ) at the linear rate of temperature changes $2{ }^{\circ} \mathrm{C} \min ^{-1}$. An empty crucible was a standard sample. Measurements were taken in inert atmosphere (helium). To avoid the white frost of the external parts of the system, the curtain gas $\left(\mathrm{N}_{2}\right)$ was used. Calibration for heat flow and temperature was done with indium and water. During the investigations, there were registered ice melting curves, which were used for determination of characteristic temperatures $T_{\max }, T_{\text {onset }}$ as well as enthalpy changes $(\Delta H)$ of phase transitions. It was assumed that $T_{\text {max }}$ corresponds to the phase transition of ice melting in the pores of medium size $\left(R_{\mathrm{av}}\right)$; however, phase changes in the pores of narrower sizes $\left(R_{\min }\right)$ correspond to the temperature of the peak start $T_{\text {onset }}$ [32]. The DSC data obtained from melting of ice confined in the pores were used for determination of sizes of water clusters bound in/to the pore walls of studied silicas. In the narrower pores, ice melts at a lower temperature than in wider pores. Mathematically, the effect of temperature decrease in ice melting inside the cylindrical pores of the $R_{\mathrm{p}}$ size is described by the Gibbs-Thomson equation (GT) [10]:

$R_{\mathrm{p}}(\mathrm{nm})=0.68-\left[k_{\mathrm{GT}} /\left(T_{\mathrm{m}}-T_{\mathrm{m} 0}\right)\right]$

where $T_{\mathrm{m}}$ and $T_{\mathrm{m} 0}$ are the melting temperatures of ice confined in the pores and outside them, respectively, $\mathrm{k}_{\mathrm{GT}}$ the constant (here: $k_{\mathrm{GT}}=32.33 \mathrm{~K} \mathrm{~nm}$ ). The curve of pore volume distribution (PSD) $\mathrm{d} V / \mathrm{d} R$ can be determined from the DSC curve of ice melting [31]:

$$
\begin{aligned}
\mathrm{d} V / \mathrm{d} R\left(\mathrm{~cm}^{3} \mathrm{~nm}^{-1} \mathrm{~g}^{-1}\right)= & {\left[\mathrm{d} q / \mathrm{d} t\left(T_{\mathrm{m}}-T_{\mathrm{m} 0}\right)^{2}\right] } \\
& /\left[k_{\mathrm{GT}} \rho \beta m \Delta H(T)\right]
\end{aligned}
$$

where $\mathrm{d} q / \mathrm{d} t$ means the heat flow, $\rho$-ice density, $\beta$ temperature changes rate, $m$ - water mass and $\Delta H(T)$-ice melting enthalpy. The density and the value of $\Delta H$ (enthalpy change of fusion) of frozen pore water, both of which depend on temperature, can be calculated from the dependences [10, 12]:

$$
\begin{aligned}
\rho(T)\left(\mathrm{g} \mathrm{cm}^{-3}\right)= & 0.917\left(1.032-1.17 \times 10^{-4} T\right) \\
\Delta H(T)\left(\mathrm{J} \mathrm{g}^{-1}\right)= & 332+11.39\left(T_{\mathrm{m}}-T_{\mathrm{m} 0}\right) \\
& +0.155\left(T_{\mathrm{m}}-T_{\mathrm{m} 0}\right)^{2}
\end{aligned}
$$

\section{Scanning electron microscopy}

Morphology of the modified silica surfaces was studied using the most versatile high-resolution, low-vacuum scanning electron microscope Quanta ${ }^{\mathrm{TM}}$ 3D FEG $\left(\mathrm{FEI}^{\mathrm{TM}}\right.$ USA). Before experiments, the samples were sprayed with platinum. 


\section{Results and discussion}

Figures 1 and 2 present the nitrogen adsorption/desorption isotherms and the incremental pore size distribution $\left(\operatorname{IPSD}_{\mathrm{v}}\right)$ curves obtained for the initial silica gel and the samples under investigations. As follows from the course of the isotherms, their shapes depend on a source of applied energy (microwave reactor, Fig. 1 or autoclave, Fig. 2) as well as on a state of medium (liquid water or overheated water vapour). As follows from the analysis of the course of adsorption isotherms, they are of type IV, while the hysteresis loops, according to the IUPAC classification [25], can be classified as $\mathrm{H} 1$ type. This is also confirmed by the values of $C_{\mathrm{BET}}$ constants $\left(C_{\mathrm{BET}}\right.$-the constant in the BET equation, Table 2) [25]. Such a kind of hysteresis loop indicates the presence of globular mesoporous structure with wide distribution of pores.

Hydrothermal modification in the microwave reactor caused that the structure of the obtained materials became more homogeneous and the observed adsorption and desorption branches (H1 type of the loop, Fig. 1a, b) are arranged almost perpendicular to the axis of relative pressures and practically parallel to each other in the range of high relative pressure values. This fact points out to the shift of IPSD ${ }_{\mathrm{v}}$ curves towards to wider pores of the tested materials (Fig. 1c, d) in relation to $\operatorname{IPSD}_{\mathrm{v}}$ curve for Si-60 ini $\left(R_{\mathrm{p}}=3.67 \mathrm{~nm}\right.$, single maximum). All silicas hydrothermally modified in the microwave reactor in the liquid phase (Si- $x_{\mathrm{m}-\text { liq }}$, Fig. 1c) are characterized by the $\mathrm{IPSD}_{\mathrm{v}}$ curves of the multiple maxima of $R_{\mathrm{p}}$ at about 30-40, 60 and $90 \mathrm{~nm}$.
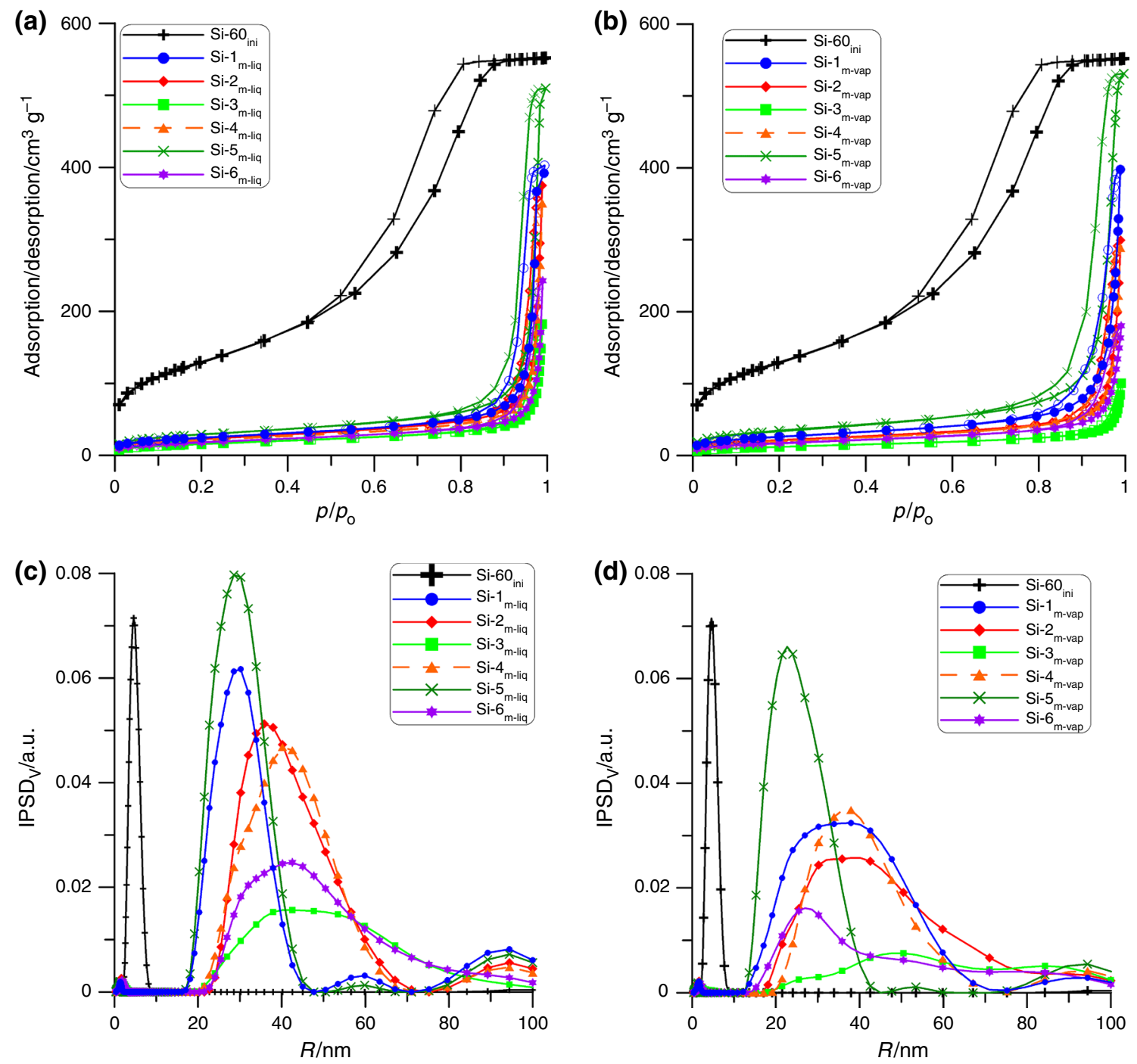

Fig. 1 Low-temperature nitrogen adsorption/desorption isotherms $(\mathbf{a}, \mathbf{b})$ as well as the incremental pore size distribution curves $\left(\mathrm{IPSD}_{\mathrm{v}}\right)(\mathbf{c}, \mathbf{d})$ for the silica gels modified in the microwave reactor

under the liquid water layer (a, c series $\mathrm{Si}-x_{\mathrm{m}-\mathrm{liq}}$ ) and in the overheated water vapour (b, d, series $\left.\mathrm{Si}-x_{\mathrm{m} \text {-vap }}\right)$ 

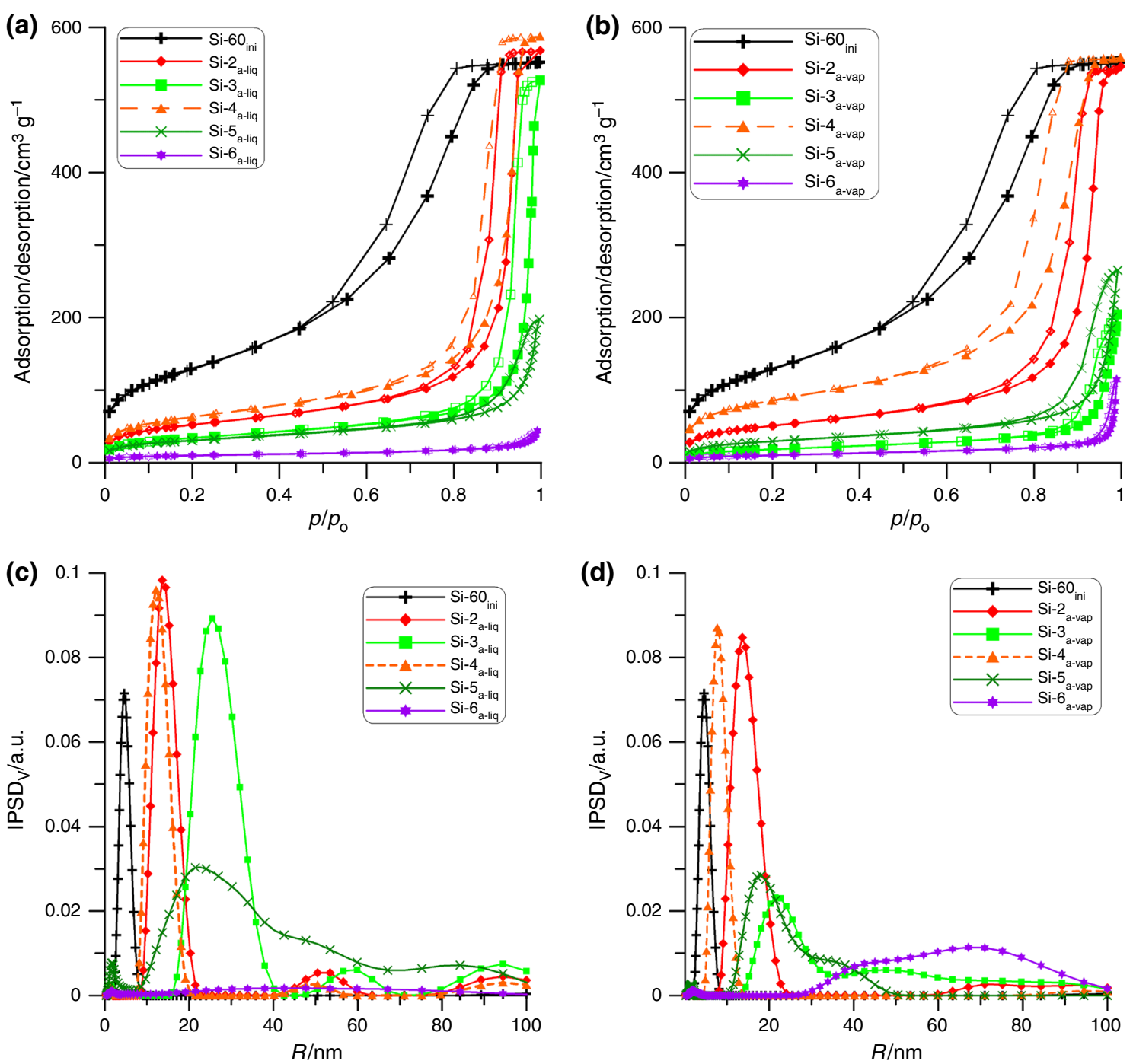

Fig. 2 Low-temperature nitrogen adsorption/desorption isotherms (a, b) as well as the incremental pore size distribution curves (IPSD $\left.{ }_{\mathrm{v}}\right)(\mathbf{c}$, d) for the silica gels modified in the autoclave under the liquid water

But in the case of silicas modified in overheated water vapour (Si- $x_{\text {m-vap }}$, Fig. 1d), we can observe $\mathrm{IPSD}_{\mathrm{v}}$ curves of bimodal character with the maxima of $R_{\mathrm{p}}$, depending on the sample at about $26-50$ and $95 \mathrm{~nm}$.

The isotherms obtained for the silica gels modified in the autoclave have a different course (Fig. 2a, b). With longer time of HTT modification process, the hysteresis loops get lower and decrease gradually in relation to shape of the loop for initial silica Si-60 ini. However, the samples in a given series ( $\mathrm{Si}-1$ and $\mathrm{Si}-4$, Fig. $2 \mathrm{c}, \mathrm{d}$ ) possess the loops of the shape similar to that of the initial silica gel hysteresis $\left(\mathrm{Si}-60_{\text {ini }}\right.$, type $\left.\mathrm{H} 1\right)$. The pore volume distribution curves indicate creation of the materials of different pore structures (Fig. 2c, d). However, one can observe the tendency towards the increase in $R_{\mathrm{p}}$ sizes with the increasing time of hydrothermal modification process.

layer (a, c, series $\left.\mathrm{Si}-x_{\mathrm{a}-\mathrm{liq}}\right)$ and in the overheated water vapour atmosphere (b, d, series $\left.\mathrm{Si}-x_{\mathrm{a}-\mathrm{vap}}\right)$

Table 2 presents the porous structure parameters of the silica gels under investigations. The analysis of these data shows that both the physical state of the modifier and the kind of energy source affect significantly the parameters of porous structure of the modified material. In the case of modification in the microwave reactor, already the short time of the HTT process (Table 1, 5 and $7 \mathrm{~min}$., for $\mathrm{Si}-1_{\mathrm{m} \text {-vap, }}$, $\mathrm{Si}-1_{\mathrm{m}-\mathrm{liq}}$, respectively) reduced the specific surface area $S_{\mathrm{BET}}$ of the modified silica gels by about $80 \%$ compared to that parameter for the initial gel ( $\mathrm{Si}-60_{\mathrm{ini}}, S_{\mathrm{BET}}=464.5 \mathrm{~m}^{2} \mathrm{~g}^{-1}$ ). Thus after modification using microwaves the specific surface area, $S_{\mathrm{BET}}$ of the sample $\mathrm{Si}-1_{\mathrm{m}-\mathrm{liq}}$ was $88.6 \mathrm{~m}^{2} \mathrm{~g}^{-1}$ but for $\mathrm{Si}-1_{\mathrm{m} \text {-vap }} S_{\mathrm{BET}}=94.4 \mathrm{~m}^{2} \mathrm{~g}^{-1}$. Extension of modification time (up to $100 \mathrm{~min}$ ) resulting in creation of changeable pressure and temperature in the system caused various changes of $S_{\mathrm{BET}}$, i.e. decrease by about $70-90 \%$ for 
Table 2 Structural parameters of the studied silica gels

\begin{tabular}{|c|c|c|c|c|c|c|c|c|c|c|}
\hline Sample & $\begin{array}{l}S_{\mathrm{BET}} / \\
\mathrm{m}^{2} \mathrm{~g}^{-1}\end{array}$ & $C_{\mathrm{BET}}$ & $\begin{array}{l}S_{\text {nano }} / \\
\mathrm{m}^{2} \mathrm{~g}^{-1}\end{array}$ & $\begin{array}{l}S_{\text {meso }} / \\
\mathrm{m}^{2} \mathrm{~g}^{-1}\end{array}$ & $\begin{array}{l}S_{\text {macro }} / \\
\mathrm{m}^{2} \mathrm{~g}^{-1}\end{array}$ & $\begin{array}{l}V_{\mathrm{p}} / \\
\mathrm{cm}^{3} \mathrm{~g}^{-1}\end{array}$ & $\begin{array}{l}V_{\text {nano }} / \\
\mathrm{cm}^{3} \mathrm{~g}^{-1}\end{array}$ & $\begin{array}{l}V_{\text {meso }} / \\
\mathrm{cm}^{3} \mathrm{~g}^{-1}\end{array}$ & $\begin{array}{l}V_{\text {macro }} / \\
\mathrm{cm}^{3} \mathrm{~g}^{-1}\end{array}$ & $\begin{array}{l}R_{\mathrm{av}} / \\
\mathrm{nm}\end{array}$ \\
\hline $\mathrm{Si}-60_{\text {ini }}$ & 464.5 & 131.97 & 31.5 & 433.1 & 0.001 & 0.944 & 0.009 & 0.844 & 0.001 & 3.67 \\
\hline $\mathrm{Si}-1_{\mathrm{m}-\mathrm{liq}}$ & 88.6 & 150.78 & 18.6 & 42.2 & 27.9 & 0.66 & 0.006 & 0.196 & 0.404 & 13.65 \\
\hline $\mathrm{Si}-2_{\mathrm{m}-\mathrm{liq}}$ & 83.0 & 119.94 & 13.7 & 37.6 & 32.1 & 0.50 & 0.004 & 0.037 & 0.409 & 7.65 \\
\hline $\mathrm{Si}-3_{\mathrm{m}-\mathrm{liq}}$ & 57.0 & 104.04 & 6.6 & 37.1 & 13.3 & 0.282 & 0.002 & 0.04 & 0.24 & 6.35 \\
\hline $\mathrm{Si}-4_{\mathrm{m}-\mathrm{liq}}$ & 78.3 & 134.32 & 16.6 & 32.9 & 28.8 & 0.542 & 0.006 & 0.044 & 0.492 & 7.45 \\
\hline $\mathrm{Si}-5_{\mathrm{m}-\mathrm{liq}}$ & 105.0 & 135.59 & 26 & 45.8 & 33.3 & 0.789 & 0.009 & 0.273 & 0.507 & 11.95 \\
\hline $\mathrm{Si}-6_{\mathrm{m}-\mathrm{liq}}$ & 66.5 & 117.07 & 11.1 & 36.2 & 19.1 & 0.374 & 0.003 & 0.035 & 0.336 & 6.3 \\
\hline $\mathrm{Si}-1_{\mathrm{m}-\mathrm{vap}}$ & 94.4 & 129.70 & 21 & 48.7 & 24.6 & 0.615 & 0.007 & 0.194 & 0.414 & 8.35 \\
\hline $\mathrm{Si}-2_{\mathrm{m}-\mathrm{vap}}$ & 77.7 & 118.68 & 15.6 & 40.3 & 21.8 & 0.463 & 0.005 & 0.085 & 0.373 & 7.05 \\
\hline $\mathrm{Si}-3_{\mathrm{m}-\mathrm{vap}}$ & 44.0 & 104.84 & 6.5 & 31.7 & 5.9 & 0.155 & 0.002 & 0.034 & 0.119 & 4.55 \\
\hline $\mathrm{Si}-4_{\mathrm{m}-\mathrm{vap}}$ & 72.6 & 117.30 & 11.1 & 37.3 & 24.2 & 0.446 & 0.004 & 0.056 & 0.386 & 7.25 \\
\hline $\mathrm{Si}-5_{\mathrm{m}-\mathrm{vap}}$ & 125.0 & 137.09 & 28.1 & 77.4 & 19.1 & 0.882 & 0.009 & 0.534 & 0.278 & 11.75 \\
\hline Si- $6_{\mathrm{m}-\mathrm{vap}}$ & 63.0 & 109.69 & 9.6 & 42.7 & 10.7 & 0.28 & 0.003 & 0.105 & 0.172 & 6.6 \\
\hline $\mathrm{Si}-2_{\mathrm{a}-\mathrm{liq}}$ & 188.1 & 140.31 & 42.9 & 144.1 & 1.2 & 0.876 & 0.014 & 0.827 & 0.035 & 9.3 \\
\hline $\mathrm{Si}-3_{\mathrm{a}-\mathrm{liq}}$ & 122.9 & 125.60 & 25.4 & 70.7 & 26.9 & 0.814 & 0.009 & 0.419 & 0.386 & 9.05 \\
\hline $\mathrm{Si}-4_{\mathrm{a}-\mathrm{liq}}$ & 226.8 & 131.98 & 50.1 & 176.1 & 0.6 & 0.909 & 0.017 & 0.873 & 0.019 & 8 \\
\hline $\mathrm{Si}-5_{\mathrm{a}-\mathrm{liq}}$ & 110.3 & 137.77 & 23.5 & 79.8 & 7 & 0.835 & 0.022 & 0.493 & 0.315 & 4.4 \\
\hline Si- $6_{a-l i q}$ & 36.3 & 220.17 & 10.1 & 24.4 & 1.8 & 0.067 & 0.003 & 0.031 & 0.033 & 3 \\
\hline $\mathrm{Si}-2_{\mathrm{a}-\mathrm{vap}}$ & 183.4 & 138.92 & 39.4 & 143.5 & 0.5 & 0.844 & 0.013 & 0.812 & 0.019 & 9.1 \\
\hline $\mathrm{Si}-3_{\mathrm{a}-\mathrm{vap}}$ & 66.6 & 131.66 & 8.6 & 50.5 & 7.4 & 0.316 & 0.003 & 0.188 & 0.125 & 7.7 \\
\hline $\mathrm{Si}-4_{\mathrm{a}-\mathrm{vap}}$ & 308.0 & 140.44 & 62.8 & 245.1 & 0.1 & 0.863 & 0.02 & 0.84 & 0.003 & 5.6 \\
\hline $\mathrm{Si}-5_{\mathrm{a}-\mathrm{vap}}$ & 106.3 & 138.54 & 23.7 & 77.4 & 5.3 & 0.395 & 0.008 & 0.31 & 0.077 & 5.85 \\
\hline Si-6 ${ }_{\mathrm{a}-\mathrm{vap}}$ & 37.7 & 147.49 & 6.7 & 24.2 & 6.9 & 0.186 & 0.002 & 0.019 & 0.156 & 5 \\
\hline
\end{tabular}

the samples modified in the microwave reactor ( $\mathrm{Si}-x_{\mathrm{m} \text {-vap }}$

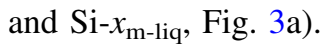

Initial $\mathrm{Si}-60_{\text {ini }}$ is a mesoporous material $\left(S_{\text {meso }}=\right.$ $433.1 \mathrm{~m}^{2} \mathrm{~g}^{-1}, V_{\text {meso }}=0.844 \mathrm{~cm}^{3} \mathrm{~g}^{-1}$, Table 2), and the mesopores surface constitutes $93.2 \%$ of its specific surface area $S_{\mathrm{BET}}$. During the HTT process due to the silica mass transport, there is created a new, much smaller mesopores surface $\left(S_{\text {meso }}\right)$ and volume $\left(V_{\text {meso }}\right.$, Table 2$)$, whereby more intensive changes take place after the process of modification under the liquid water layer (series $\mathrm{Si}-x_{\mathrm{m}-\mathrm{liq}}$ ). Figure $3 \mathrm{~b}$ presents the course of changes in the mesopores surface of the studied materials. As we can see, the contribution of mesopores to the porous structure of silica gels modified in the microwave reactor is in the range $40-70 \%$.

HTT performed in the microwave reactor also contributed to development of the nanoporous structure $\left(S_{\text {nano }}\right.$, $V_{\text {nano, }}$ Table 2). In the case of the initial silica gel Si-60 $0_{\text {ini }}$, nanopores constituted only $6.8 \%$. However, due to HTT modification, contribution of nanopores to the structure of the series of gels under investigations (series $\mathrm{Si}-x_{\mathrm{m}-\mathrm{vap}}$ and Si- $x_{\mathrm{m}-\mathrm{liq}}$ ) increased up to about $12-22 \%$ (Fig. 3c). However, because of the decrease in specific surface area $S_{\mathrm{BET}}$ of the modified materials, there is observed a decrease in
$S_{\text {nano }}$ compared to that of the initial silica (Table 2). Due to the silica mass transport, there were created also macropores $\left(S_{\text {macro }}, V_{\text {macro }}\right)$ and the average radius of pores $R_{\mathrm{av}}$ significantly increased in all analysed samples (Table 2).

Somewhat different dependences were observed for the samples modified in the classical autoclave ( $\mathrm{Si}-x_{\mathrm{a}-\mathrm{vap}}$, $\left.\mathrm{Si}-x_{\mathrm{a}-\mathrm{liq}}\right)$. Under these conditions, the parameters steering the course of the process are initially established temperature and time. Pressure of the overheated water vapour in such a system depends on the state of water (liquid or vapour) and the degree of silica modification depends on the hydrothermal process time. The longer modification time and the higher temperature are, the greater are changes of structural parameters (Table 2). In both series of silica gels: $\mathrm{Si}-x_{\mathrm{a}-\mathrm{liq}}$ and $\mathrm{Si}-x_{\mathrm{a}-\mathrm{vap}}$, there was observed a decrease in the specific surface area $S_{\mathrm{BET}}$ (Table 2; Fig. 3a) depending on the process conditions. The observed changes do not proceed as intensively as it was found for the samples modified in the microwave reactor (Fig. 3a). This is connected with a different way of heating samples in the systems: microwave radiation causes quick, volumetric heating of the whole mass of the sample, but in the autoclave the sample is heated from the outside and the process 

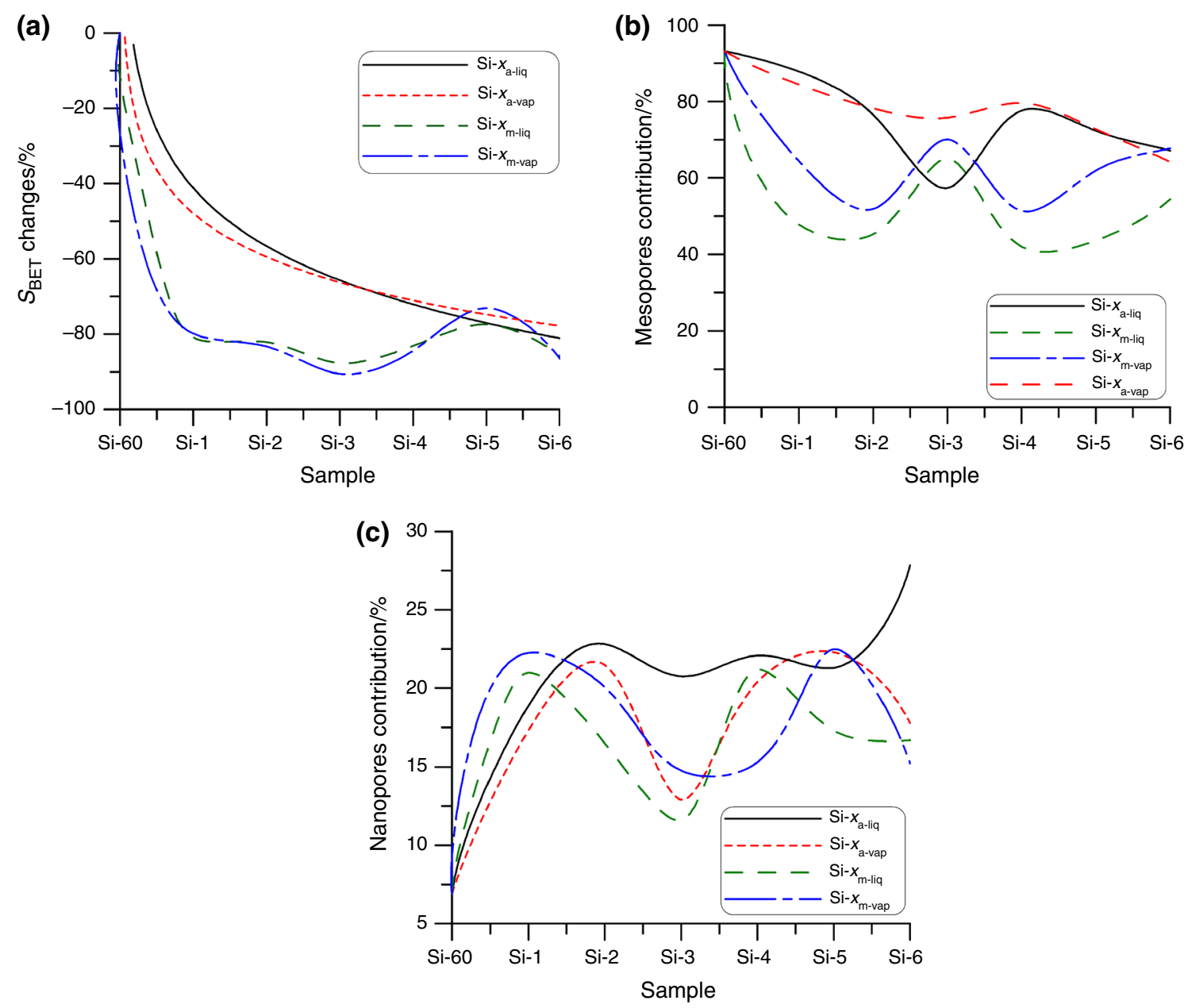

Fig. 3 Decrease in the specific surface area $S_{\mathrm{BET}}$ (a) and contribution of meso- (b) and nanopores (c) surface for the initial silica gel and silicas hydrothermally modified in the microwave reactor and autoclave

is less intensive. This causes differentiation of the HTT process course. Creating a porous structure in the autoclave leads to preparation of the materials whose nanopores constitute about $20 \%$ of the total surface, but contribution of mesopores is up to $80 \%$ (Fig. $3 \mathrm{~b}$ ). The materials prepared in this way are characterized by much smaller contribution of macropores but larger one of nano- and mesopores than it was observed for the materials prepared due to modification in the microwave reactor (Table 2).

Figure 4a presents the curves of ice melting in the pores of silica gels of the exemplary $\mathrm{Si}-x_{\mathrm{m}-\text { liq }}$ series. In all studied series of adsorbents, thermal effects of phase transitions occur in the temperature range $-40{ }^{\circ} \mathrm{C}$ to $+20{ }^{\circ} \mathrm{C}$. The shifts of transitions start $T_{\text {onset }}$ (marked with arrows in Fig. 4a) result from redevelopment of surface and structure of pores. The curves for the other three series of silicas (Si$x_{\mathrm{m}-\mathrm{vap}}, \mathrm{Si}-x_{\mathrm{a}-\text { liq }}$ and $\left.\mathrm{Si}-x_{\mathrm{a}-\mathrm{vap}}\right)$ have similar shapes to that of the exemplary one (Fig. 4a) but differ in shift of characteristic temperatures $T_{\text {onset }}$ and $T_{\max }$. The course of temperature changes ( $T_{\text {onset }}$ and $\left.T_{\max }\right)$ is presented in Fig. $4 \mathrm{~b}$.
It is commonly known that water confined inside pores, particularly in the materials of strong hydrophilic properties, is characterized by different physicochemical properties from these of bulk water. In the case of the initial material $\left(\mathrm{Si}-60_{\text {ini }}\right)$, the peak of confined ice melting $\left(T_{\text {onset }}\right)$ begins at a temperature about $-17{ }^{\circ} \mathrm{C}$, but the maximum $\left(T_{\max }\right)$ is reached at a temperature about $-10{ }^{\circ} \mathrm{C}$ (Fig. 4a). Such reduction in the transition temperature compared to the parameters registered for the free ice is due to its strong interaction with the silica surface. A gradual increase in $T_{\text {onset }}$ and $T_{\max }$ is observed for the samples modified under the liquid water layer ( $\mathrm{Si}-x_{\mathrm{a}-\mathrm{liq}}$ and $\mathrm{Si}-x_{\mathrm{m}-\mathrm{liq}}, \mathrm{Fig}$. $4 \mathrm{~b}$ ). Different changes are observed during modification in the water vapour atmosphere ( $\mathrm{Si}-x_{\mathrm{a}-\mathrm{vap}}$ and $\left.\mathrm{Si}-x_{\mathrm{m} \text {-vap}}\right)$. A gradual reduction in $T_{\text {onset }}$ temperature in this series takes place. As we can see, the course of analysed parameters changes is almost of linear character (Fig. 4b). The most differentiated changes were found after the modification in the overheated water vapour atmosphere in the autoclave (Si- $\left.x_{\mathrm{a}-\mathrm{vap}}\right)$. With the increasing $T_{\max }$, the $T_{\text {onset }}$ values 

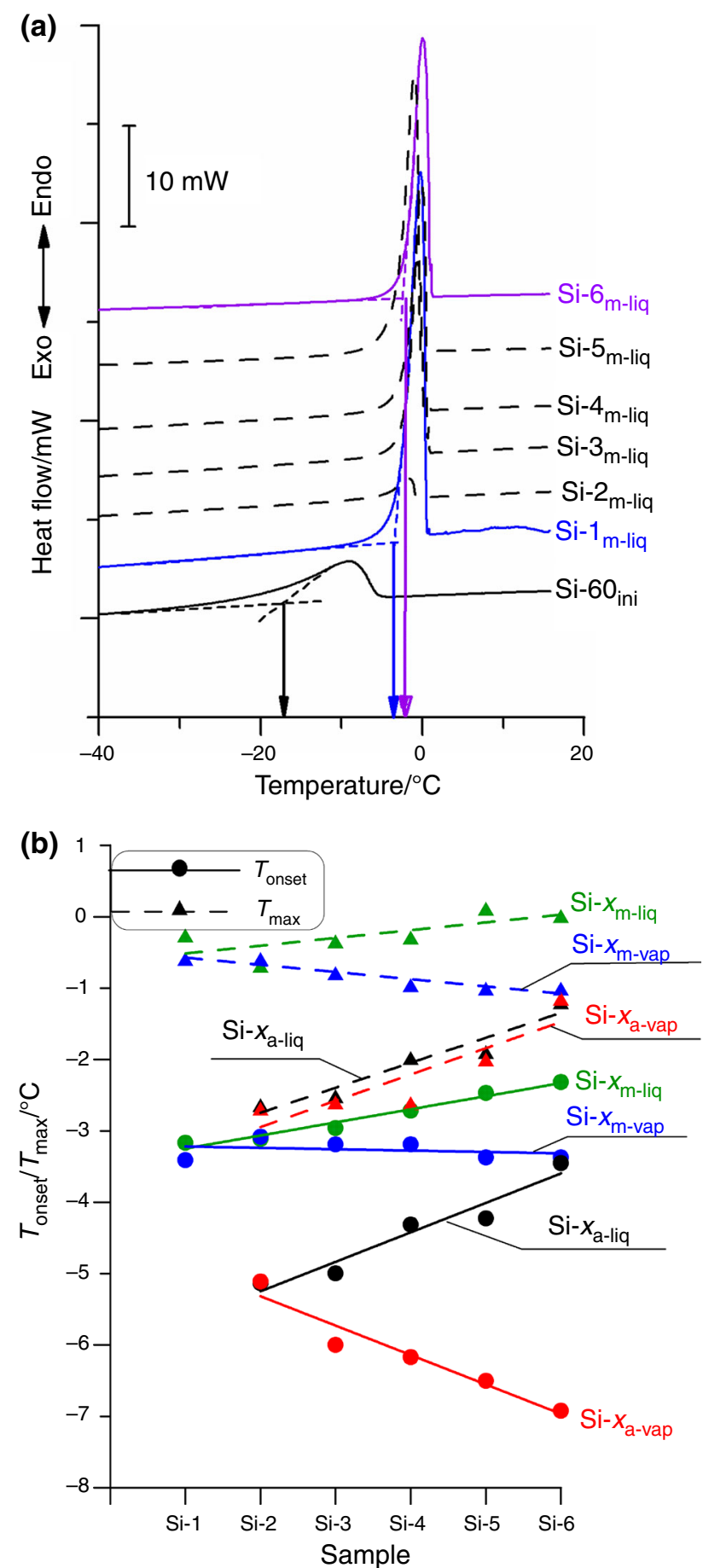

Fig. 4 Exemplary curves DSC of ice melting in pores of the modified silica gels series Si- $x_{\mathrm{m}-\mathrm{liq}}(\mathbf{a})$ and course of temperature changes $T_{\text {onset }}$ and $T_{\max }(\mathbf{b})$

decreased. Such course of changes indicates an increase in $R_{\text {av }}$ with the simultaneous decrease in $R_{\min }$ values in this series of silicas (see also Figs. 2, 3c; Table 2). At the same time, all determined characteristic temperatures are much higher than the corresponding temperature for the initial

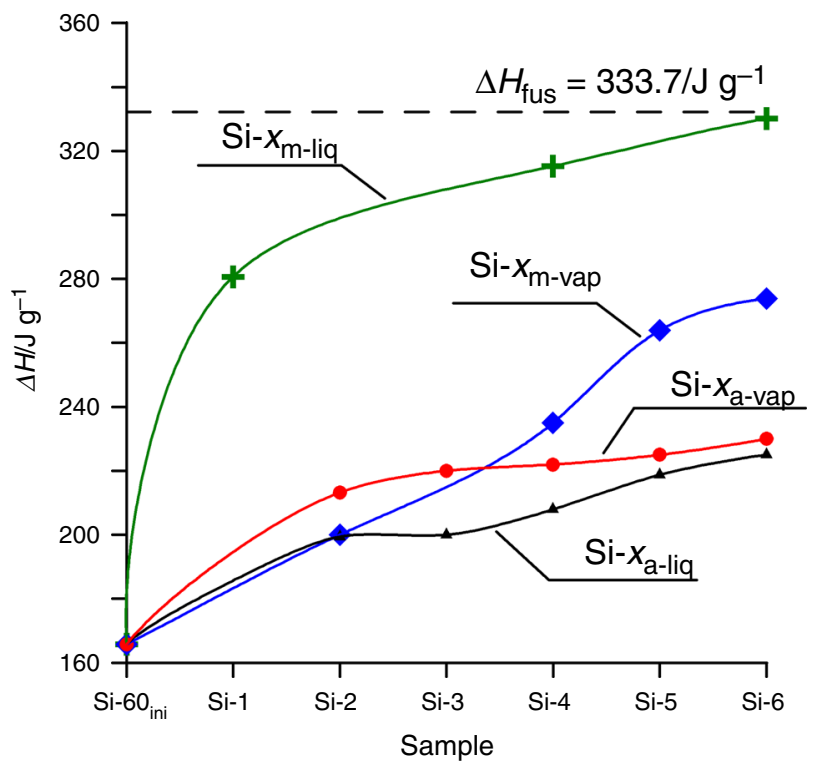

Fig. 5 Changes of the enthalpy of phase transition $(\Delta H)$ determined from the DSC curves of ice melting confined in the pores of the analysed silicas

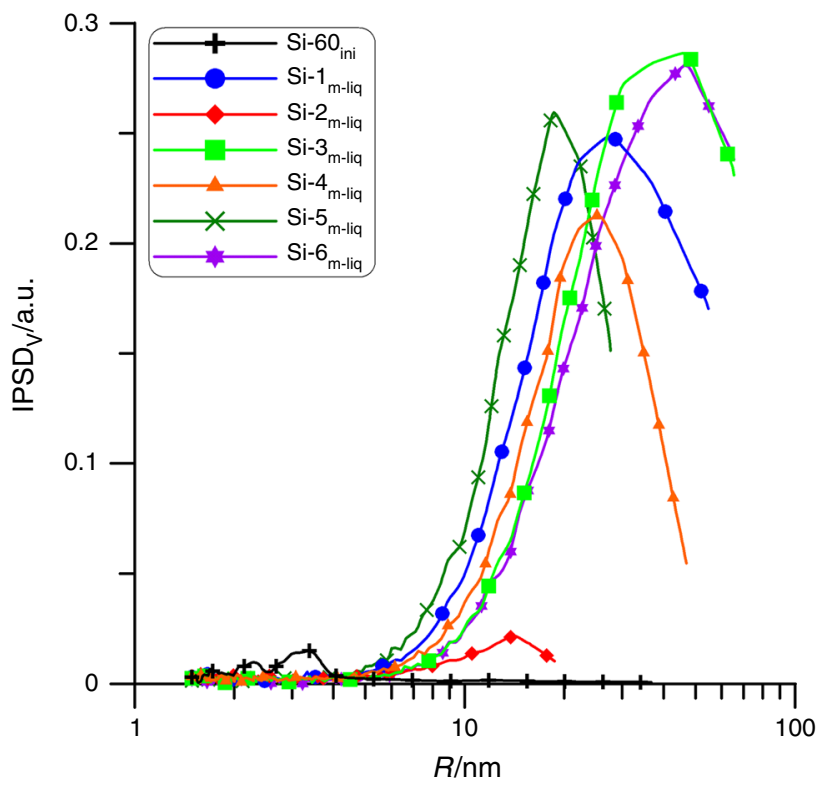

Fig. $6 \operatorname{IPSD}_{\mathrm{v}}$ curves determined from the DSC curves for the series of silica gels modified in the microwave reactor in the presence of liquid water $\left(\mathrm{Si}-x_{\mathrm{m}-\mathrm{liq}}\right)$

silica gel which is the evidence of intensive changes in the porous structure due to hydrothermal modification.

Figure 5 shows the changes of melting enthalpy of ice confined in the pores of the silicas under investigations. The dependence shows that in the case of all hydrothermal modification procedures (under different conditions), the obtained $\Delta H$ values are lower than that of the specific heat of fusion $\left(\Delta H_{\text {fus }}=333.4 \mathrm{~J} \mathrm{~g}^{-1}\right)$. Simultaneously, we can 
observe the increase in the $\Delta H$ values in a series of silicas (from $\mathrm{Si}-1$ to $\mathrm{Si}-6$ ), wherein the fastest value close to $\Delta H_{\text {fus }}$ is achieved in the case of silicas of $\mathrm{Si}-x_{\mathrm{m}-\text {-liq }}$ series. This indicates that the conditions of phase transition occurring in the pores of a series of silica $\mathrm{Si}-x_{\mathrm{m}-\mathrm{liq}}$ are most similar to those of the phase transition of the free ice melting $\left(T_{\max }=0{ }^{\circ} \mathrm{C}\right)$. These observations are consistent with the values of $T_{\max }$ (close to $0{ }^{\circ} \mathrm{C}$ ) presented in Fig. $4 \mathrm{~b}$.

Figure 6 presents the exemplary $\operatorname{IPSD}_{\mathrm{v}}$ curves determined from the DSC curves for the series of silica gels modified in a microwave reactor in the presence of liquid water $\left(\mathrm{Si}-x_{\mathrm{m}-\mathrm{liq}}\right)$. As follows from the curves, there is a significant increase in the sizes of the pores $R_{\mathrm{av}}$ found for the hydrothermally modified materials compared to the initial material $\left(\mathrm{Si}-60_{\text {ini }}\right)$. The maxima on the $\mathrm{IPSD}_{\mathrm{v}}$ curves shift towards higher values with longer time of hydrothermal modification. These observations are consistent with the results obtained based on the nitrogen adsorption/desorption data (Table 2).

Figure 7 presents the SEM images obtained for the initial silica gel Si-60 ini (Fig. 7a) and for the gels Si-6 obtained in all used systems $\left(\mathrm{Si}-6_{\mathrm{m}-\mathrm{liq}}, \mathrm{Si}-6_{\mathrm{m}-\mathrm{vap}}, \mathrm{Si}-6_{\mathrm{a}-\mathrm{li}}\right.$
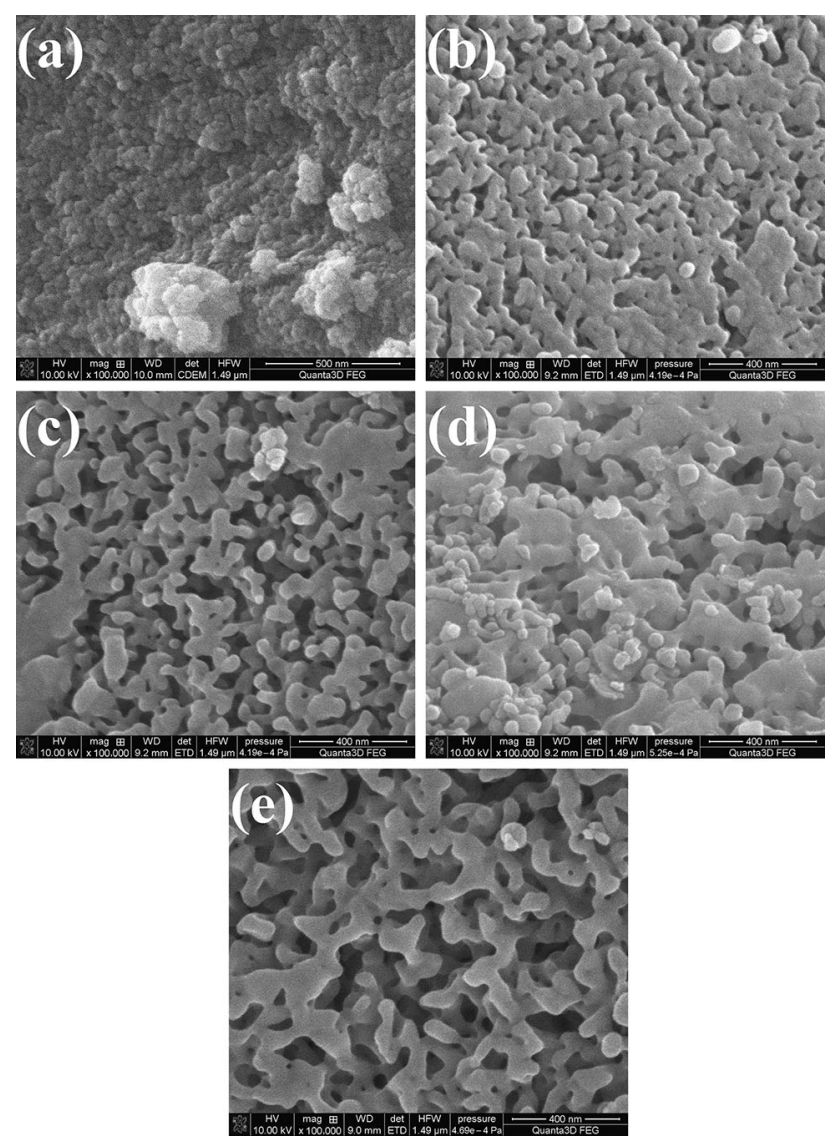

Fig. 7 SEM images (magnification $\times 100,000$ ) of the silica gels Si$60_{\text {ini }}(\mathbf{a})$, Si- $6_{\text {m-liq }}(\mathbf{b})$, Si- $6_{\text {m-vap }}(\mathbf{c})$, Si- $6_{\text {a-liq }}(\mathbf{d})$ and Si-6 $6_{\text {a-vap }}(\mathbf{e})$ and $\mathrm{Si}-6_{\mathrm{a}-\mathrm{vap}}$, Fig. $7 \mathrm{~b}-\mathrm{e}$, respectively). According to the data in Table 2, the surface of these samples was modified to the greatest extent.

Numerous inequalities can be observed on the $\mathrm{Si}-60_{\text {ini }}$ surface (Fig. 7a); however, generally their structure is clearly globular. The primary and secondary particles forming aggregates and agglomerates can be observed, and the surface is expanded and corrugated.

The HTT of porous silicas enhances the average pore size and reduces the specific surface area and pore sizes (Table 2). Due to the hydrothermal modification, the surface becomes reconstructed, and single globules and small aggregates disappear (they were dissolved during the HTT process) and deposit on the surface of larger molecules. Then, the average size of silica particles increases. This is because of mass transferring from smaller particles to larger ones and their tighter merger due to the coverage of their contact space by transferred silica. The system of wide canals of different sizes is created (Fig. 7b-e). The new structures take a spongy form. The analysis of SEM images shows that the structure of the materials obtained during modification in the oversaturated water vapour atmosphere ( $\left.\mathrm{Si}-6_{\mathrm{a}-\mathrm{vap}}, \mathrm{Si}-6_{\mathrm{m} \text {-vap }}\right)$ is more homogeneous and ordered. Figure $7 \mathrm{c}$, e does not show small sizes clusters which, despite similar conditions of modification, remain in the structure of the silicas modified under a liquid water layer (Fig. 7b, d).

\section{Conclusions}

The studies proved that hydrothermal modification causes intensive changes of silica material surface. Size and character of changes depend on both the kind of system (liquid water or overheated water vapour) and the source of energy (microwave reactor or steel autoclave). Rebuilding of the surface caused by the presence of a modifying agent, connected with a silica mass transport under hydrothermal conditions resulted (in all cases) in a significant decrease in the specific surface area $S_{\mathrm{BET}}$ and mesopores surface $\left(S_{\text {meso }}\right)$ as well as the volume of the pores $V_{\mathrm{p}}$ and $V_{\text {meso }}$. At the same time, an increase in the contribution of nanopores in the structure of the studied materials is observed. The most intensive changes were found during modification in microwaves under the liquid water layer (series $\mathrm{Si}-x_{\mathrm{m}-\mathrm{liq}}$ ). Similar changes but less intensive were observed after modification in the classical autoclave.

The materials are characterized by a wide pores distribution. Hydrothermal modification in the microwave reactor caused that the structure of the obtained materials is characterized by bimodal ( $\left.\mathrm{Si}-x_{\mathrm{m}-\mathrm{vap}}\right)$ or multimodal $\left(\mathrm{Si}-x_{\mathrm{m}-\mathrm{liq}}\right)$ $\mathrm{IPSD}_{\mathrm{v}}$ shapes. However, during modification in the classical autoclave the pores of different structures and sizes were 
created, but there can be seen a tendency of $R_{\mathrm{av}}$ increase with the increasing time of hydrothermal modification process.

Strong interactions of water molecules confined in the silica pores resulted in lowering of ice melting points. The SEM analysis of the modified materials surface exhibited a globular structure of aggregates and agglomerates Si- $60_{\text {ini }}$ as well as a spongy structure of the hydrothermally modified materials because of their tighter connections due to the coverage of contact space by the transferred silica.

Open Access This article is distributed under the terms of the Creative Commons Attribution 4.0 International License (http://crea tivecommons.org/licenses/by/4.0/), which permits unrestricted use, distribution, and reproduction in any medium, provided you give appropriate credit to the original author(s) and the source, provide a link to the Creative Commons license, and indicate if changes were made.

\section{References}

1. Bergna HE, editor. The colloidal chemistry of silica. Washington: American Chemical Society; 1994.

2. Iler RK. The chemistry of silica. New York: Wiley; 1979.

3. Leboda R, Mendyk E, Tertykh VA. Effect of the hydrothermal treatment method in an autoclave on the silica gel porous structure. Mater Chem Phys. 1995;42:7-11.

4. Leboda R, Tertykh VA, Sidorchuk VV, Skubiszewska-Zięba J. Peculiarities of steam-phase hydrothermal modification of pyrogenic silicium dioxide. Colloid Surf A. 1998;135:253-65.

5. Leboda R, Mendyk E, Gierak A, Tertykh VA. Hydrothermal modification of silica gels (xerogels) 1. Effect of treatment temperature on their porous structure. Colloid Surf A. 1995;105:181-9.

6. Leboda R, Mendyk E, Gierak A, Tertykh VA. Hydrothermal modification of silica gels (xerogels) 2. Effect of the duration of treatment on their porous structure. Colloid Surf A. 1995;105:191-7.

7. Leboda R, Mendyk E, Tertykh VA. Effect of medium $\mathrm{pH}$ on hydrothermal treatment of silica gels (xerogels) in an autoclave. Mater Chem Phys. 1996;43:53-8.

8. Skubiszewska-Zięba J. Structural and energetic properties of carbosils hydrothermally treated in the classical autoclave or the microwave reactor. Adsorption. 2008;14:695-709.

9. Skubiszewska-Zięba J. The impact of microwave energy on the results of silica gel hydrothermal modification. Adsorption. 2010;16:485-93.

10. Landry MR. Thermoporometry by differential scanning calorimetry: experimental considerations and applications. Thermochim Acta. 2005;433:27-50.

11. Gun'ko VM, Turov VV. Nuclear magnetic resonance studies of interfacial phenomena. New York: Taylor \& Francis; 2013.

12. Ishikiriyama K, Todoki M, Motomura K. Pore size distribution (PSD) measurements of silica gels by means of differential scanning calorimetry, Part I, Optimization for determination of PSD. J Colloid Interface Sci. 1995;171:92-102.

13. Ishikiriyama K, Todoki M. Pore size distribution (PSD) measurements of silica gels by means of differential scanning calorimetry. Part II. Thermoporosimetry. J Colloid Interface Sci. 1995;171:103-11.
14. Endo A, Yamamoto T, Inagi Y, Iwakabe K, Ohmori T. Characterization of nonfreezable pore water in mesoporous silica by thermoporometry. J Phys Chem C. 2008;112:9034-9.

15. Riikonen J, Salonen J, Lehto VP. Utilising thermoporometry to obtain new insights into nanostructured materials-part I. J Therm Anal Calorim. 2011;105:811-21.

16. Brun M, Lallemand A, Quinson J, Eyraud C. A new method for the simultaneous determination of the size and the shape of pores. Thermochim Acta. 1977;21:59-88.

17. Charmas B. Adsorption and calorimetric studies of properties of hydrothermally modified carbosils. J Therm Anal Calorim. 2014;115:1395-405.

18. Charmas B. TG and DSC studies of bone tissue. Effects of osteoporosis. Thermochim Acta. 2013;573:73-81.

19. Takei T, Nakada M, Yoshikawa N, Hiroe Y, Yoshida H. Effect of organic functional groups on the phase transition of organic liquids in silica mesopores. $\mathrm{J}$ Therm Anal Calorim. 2016;123:1787-94.

20. Majda D, Makowski W, Manko M. Pore size distribution of micelle-templated silicas studied by thermoporosimetry using water and n-heptane. J Therm Anal Calorim. 2012;109:663-9.

21. Majda D, Zimowska M, Tarach K, Góra-Marek K, Napruszewska $\mathrm{BD}$, Michalik-Zym A. Water thermoporosimetry as a tool of characterization of the textural parameters of mesoporous materials. Refinement of the methodology. J Therm Anal Calorim. 2017;. doi:10.1007/s10973-016-5400-3.

22. Gun'ko VM, Turov VV, Bogatyrev VM, Zarko VI, Leboda R, Goncharuk EV, Novza AA, Turov AV, Chuiko AA. Unusual properties of water at hydrophilic/hydrophobic interfaces. Adv Colloid Interface. 2005;118:125-72.

23. Wang LP, Wang TB, Gao CF, Lan X, Lan XZ. Phase behavior of dodecane-hexadecane mixtures in bulk and confined in SBA-15. J Therm Anal Calorim. 2014;116:469-76.

24. Gajewska I, Najberg H, Senderacka I, editors. Physicochemical handbook. Warsaw: Scientific-Technical Publishing; 1962.

25. Gregg SJ, Sing KSW. Adsorption, surface area and porosity. London: Academic Press; 1982.

26. Gun'ko VM, Do DD. Characterizations of pore structure of carbon adsorbents using regularisation procedure. Colloid Surf A. 2001;193:71-83.

27. Gun'ko VM. Consideration of the multicomponent nature of adsorbents during analysis of their structural and energy parameters. Theor Exp Chem. 2000;36:319-24.

28. Gun'ko VM, Turov VV, Leboda R, Skubiszewska-Zięba J, Charmas B. Confined space effects driving to heterogenization of solutions at the interfaces. Adsorption. 2013;19:305-21.

29. Skubiszewska-Zięba J, Charmas B, Leboda R, Tertykh VA, Yanishpolskii VV. Complex investigations of structural and thermal properties of silica-titania adsorbents. J Therm Anal Calorim. 2012;108:1085-92.

30. Kjeldsen AM, Geiker MR. On the interpretation of low temperature calorimetry data. Mater Struct. 2008;41:213-24.

31. Gun'ko VM, Savina IN, Mikhalovsky SV. Cryogels: morphological, structural and adsorption characterisation. Adv Colloid Interface. 2013;187-188:1-46.

32. Gun'ko VM, Mikhalovsky SV. Evaluation of slitlike porosity of carbon adsorbents. Carbon. 2004;42:843-9. 